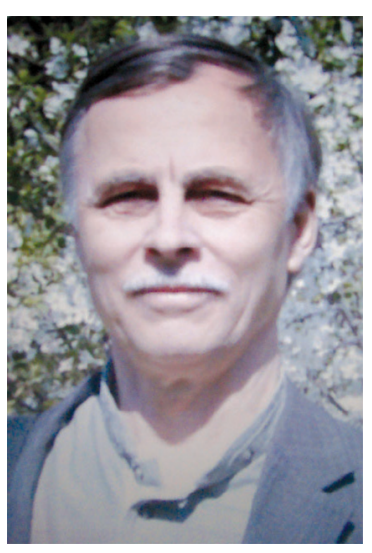

\section{Тертычный Александр Алексеевич}

доктор филологический наук, профессор

кафредра периодической печати факультета

журналистики, Московский государственный университет им. М. В. Ломоносова,

125009, Российская Федерация, г. Москва, ул. Моховая, 9, e-mail: tertaa@yandex.ru

\section{Alexandr A. Tertychnyi}

DSc in Philology, Professor,

Department of Periodical Press, Faculty of Journalism, Lomonosov Moscow State University,

9 Mokhovaya St., 125009, Moscow, Russian Federation, e-mail: tertaa@yandex.ru

\title{
ПРОГНОЗ В ЖУРНАЛИСТСКОМ ТЕКСТЕ: ОСОБЕННОСТИ ОБОСНОВАНИЯ
}

Аннотация. Автор данной статьи исходит из того, что прогнозирование является одной из важнейших функций современной журналистики, поскольку знание о развитии в будущем тех или иных, значимых для общества явлений, постоянно востребуется аудиторией. То, насколько журналистский прогноз может быть использован в практической жизни аудитории, во много зависит от её доверия к нему. Возникновение такого доверия предопределяется рядом условий, важнейшим из которых выступает прозрачность обоснования прогноза автором, ясность, убедительность авторских выводов относительно прогнозируемого явления. Подобная ясность, обоснованность прогноза могут быть достигнуты прежде всего в результате применения тех или иных, понятных аудитории методов прогнозирования. Существует множество методов составления прогнозов, применяемых в разных сферах деятельности и адаптированных к тем или иным задачам, решению которых они способствуют. Теоретический анализ и исследование конкретных журналистских текстов, позволили автору статьи утверждать, что в ходе прогнозирования, в них чаще всего применяются такие методы, как «причинно-следственный анализ», «метод сценариев», «экстраполяции», «аналогии», «экспертных оценок» и «ссылки на позитивный опыт». Именно на анализе особенностей использования в ходе прогнозирования этих методов и сосредоточено внимание автора в данной статье. Каждый из названных методов обладает своими возможностями, знание которых помогает при подготовке журналистской публикации выбирать наиболее оптимальные из них (применительно к конкретной ситуации прогнозирования) и избегать, в результате, возможных ошибок, добиваясь ясности и понятности прогнозов для аудитории, а, значит, и создавать предпосылки её доверия к ним.

Ключевые слова. Прогноз в журналистском тексте, методы прогнозирования, обоснование прогнозов, доверие к прогнозам.

Информация о статье. Дата поступления 14 марта 2017 г.; дата принятия к печати 05 мая 2017 г.; дата онлайн-размещения 08 июня 2017 г. 


\title{
FORECASTS IN JOURNALISTIC TEXTS: SPECIFIC CRITERIA FOR GROUNDING
}

\begin{abstract}
The author assumes that forecasting is one of the most important functions of modern journalism, since audiences are always interested in knowing how different significant social phenomena will develop in the future. How a journalistic forecast can be used in practical life of the audience depends largely on its credibility. The occurrence of such trust is determined by a number of conditions, the most important of which is the transparency of the substantiation of the forecast by the author, clarity, credibility of the author's conclusions regarding the predicted phenomenon. Such clarity, the validity of the forecast can be achieved primarily as a result of applying different methods of forecasting understandable to the audience. There are many methods of forecasting used in various fields and adapted to solving different tasks. Theoretical analysis and study of specific journalistic texts have allowed the author to assert that forecasting, journalists often apply such methods as "cause and effect analysis», "scenario method», "extrapolation method», «analogy method», «expert evaluation method» and «references to positive experiences method». In the article the author focuses on the peculiarities of using these methods in journalistic forecasts. Each of the methods considered has its own possibilities, knowing which helps one to choose the most suitable methods to apply in a particular forecasting context while preparing a journalistic publication and avoid possible mistakes, thus contributing to forecasts being clear and understandable to the audience, and thus making those forecasts more credible for the audience.
\end{abstract}

Keywords. Forecast in journalistic text, methods of forecasting, justification of predictions, forecasts credibility.

Article info. Received March 14, 2017; accepted May 05, 2017; available online June 08, 2017.

Тексты, представляющие собой изложение прогнозов относительно развития определенных явлений в будущем, то есть, прогностические тексты, выступают одним из важнейших содержательных факторов современной аналитической журналистики [1, с. 54-57], поскольку «прогностическая функция - наиважнейшая, неотъемлемая составляющая журналистики...» [2, с. 1]. Обращение к ним аудитории продиктовано желанием или необходимостью сориентироваться в возможном возникновении или будущем состоянии уже существующих феноменов, ради того, чтобы действовать более целенаправленно, более осознанно в настоящем [3, р. 17-57]. Само собой разумеется, что прогноз будет учитываться аудиторией, только в случае, если будет вызывать у неё доверие к себе. От чего зависит такое доверие? Главным условием его можно было бы назвать достоверность прогноза. Однако утверждать это было бы правильно, если бы можно было каким-то образом убеждаться в его достоверности. Но возможно ли это? Напомним, что под достоверностью любых утверждений, в том числе и прогностических, понимается соответствие их содержанию предмета, 
к которому они относятся. Такое соответствие, как известно, устанавливается путем сравнения знания, заключенного в утверждении, с реальным содержанием явления, которое в этом знании отражается. Однако, что касается прогноза, то в момент составления его, само явление (или качества его), которые он отражает, ещё не существуют. Поэтому момент верификации прогноза тоже отсутствует. Это состояние длится до тех пор, пока прогнозируемое явление не станет реальностью. До этого проверить достоверность прогноза невозможно.

Тем не менее, вполне уместно рассуждать о другой стороне прогноза, учитывая которую, можно повысить доверие аудитории к нему. Это сторона - ясность пути, понятность аргументации и её убедительность, которые приводят автора прогностического текста к тем или иным утверждениям о будущем. И чем яснее будет показан путь развития прогноза, чем весомее доводы, которые привели автора публикации к данному прогностическому утверждению, тем приемлемее оно будет для аудитории.

Напомним, что основой любого прогноза выступает связь между каким-то уже существующим феноменом, качества которого известны, и пока не существующим феноменом, возникновение которого предполагается в будущем, качества которого неизвестны, но установление которых необходимо. Именно эта связь должна быть проявлена максимально ясно, и в максимально доступной степени обоснована автором в прогностическом тексте. Подобную связь между сущим и возможным, её обосно- вание, осуществляют с помощью разных методов, отражающих то, или иное, из взаимоотношений между явлениями реальности, воспринимаемых познающим субъектом как закономерные. Этих методов множество [4, с. 43-45], и они обладают разными возможностями, которые по-своему способствуют восприятию аудиторией публикуемых разнообразных прогнозов [5, c. 104], как засуживающих доверия.

Наши наблюдения показывают, что чаще всего авторы прогнозов в журналистских текстах обращаются к таким методам их обоснования, как «причинно-следственный анализ», «метод сценариев», «экстраполяции», «аналогии», «экспертных оценок» и «ссылки на опыт» (опыт получения желаемого результата). Рассмотрим последовательно возможности каждого из этих методов в обосновании прогноза в журналистском тексте.

Метод «причинно-следственного анализа» в прогнозировании применяется, по нашим наблюдениям, наиболее активно. Напомним, что «причинная зависимость выступает парной генетической связью явлений, из которых одно (причина) порождает другое (следствие)» [6, с. 141]. В случае прогнозирования автор исследует причинно-следственную связь между уже существующими фактами и предполагаемыми, пока не существующими. Прослеживая такую связь, он, как раз, может вполне уверенно рассуждать о грядущих следствиях сегодняшних событий. Основой такой уверенности обычно служит его, неоднократно подтверждавшееся знание, о том, что из определенных явлений (причин) обычно вытекают 
некие другие определенные явления (следствия), к которым могут относиться и прогнозируемые автором.

Прогноз, опирающийся на причинно-следственную связь, содержится, например, в публикации «Кого Путин выберет канцлером Германии» [7, с. 1]. Часть её, собственно излагающую прогноз, автор начинает суждением, представляющим собой главную, обосновываемую далее, мысль выступления:

«...Но обращаюсь к главной теме этой статьи, а именно: пойдёт ли Меркель на четвёртый срок своего канцлерства. А в том, что пойдёт сомнений нет, даже несмотря на некоторую «интрижку», затеянную сейчас на немецком политическом Олимпе. После того, как в минувший вторник, 15 ноября, председатель комиссии Бундестага по внешней политике Норберт Рёттген в интервью CNN вдруг заявил, что Меркель намерена в четвёртый раз баллотироваться на пост канцлера, назвав её «краеугольным камнем западной политической концепции» и «активным глобальным политическим игроком», официальный представитель правительства ФРГ Штеффен Зайберт отказался подтвердить слова Рёттгена. «Ангела Меркель выскажется по данному вопросу в подходящее для этого время, как мы уже неоднократно заявляли», - ответил Зайберт на вопрос агентства Reuters. Но всё это не более, чем игра словами. Конечно, Меркель на четвёртый срок пойдёт».

Далее автор анализирует сложившуюся на сегодняшний день общественно-политическую ситуацию в Германии. Он, с одной стороны, приводит и оценивает факты, которые выступают аргументами в пользу того, что Меркель намерена в четвёртый раз баллотироваться на пост канцлера, а, с другой, - сообщает о фактах, которые противостоят этому намерению. Ниже мы последовательно излагаем текст с нашими пояснениями (они помечены знаком «А.Т.»):

1) Факты «за» (А.Т.): «Пойдет, хотя бы уже потому, что, как показало ноябрьское исследование, проведённое НИИ изучения общественного мнения и статистического анализа Forsa, за её выдвижение на этот пост высказались 59\% из 1002 респондентов по всей Германии. Причём среди сторонников партии Христианско-демократический союз (ХДС) таковых даже $87 \%$, и около $60 \%$ среди сторонников «сестринской» партии Христианско-социальный союз (ХCC).

2) Факты «против» (А.Т.): «Впрочем есть некоторые основания этим данным не верить.

Во-первых, в самой ХДС из-за насаждаемой председателем партии Ангелой Меркель политики в отношении беженцев давно идут «разброд и шатания», усилившиеся после провальных итогов осенних выборов в ряд региональных парламентов (ландтагов).

Во-вторых, в последние месяцы между «сёстрами» ХДС и ХСС постоянно растёт напряжённость прежде всего из-за всё той же миграционной политики. Дошло до того, что на свой очередной съезд, состоявшийся в начале ноября в Мюнхене, ХСС, вопреки устоявшейся традиции, главу ХДС Меркель вообще не пригласил».

3) Факты «за» (А.Т.): «Хотя, возможно, это было сделано с благородной целью помочь фрау бундескан- 
цлерин «сохранить лицо». Потому что на съезде ХСС была принята новая партийная программа, красноречиво названная «Die Ordnung» («Порядок»), в которой провозглашены, в частности:

- отказ партии от построения в Германии мультикультурного общества;

- признание немецкой культуры, доминирующей и основой для консенсуса в стране;

- недопущение развития в Германии политического ислама;

- невозможность создания коалиции с социал-демократами, «зелёными» и «левыми».

Кроме того, ХCС подтвердил своё прежнее требование установить верхний предел численности принимаемых иммигрантов. Но невзирая на то, что все эти программные требования идут полностью вразрез с политикой канцлера, Ангела Меркель, собираясь в четвёртый раз возглавить кабинет, весьма грамотно расчищает себе дорогу».

4) Факты «против» (А.Т.): «Ещё в сентябре опрос общественного мнения показал, что самым популярным политиком Германии является министр иностранных дел, социалдемократ Франк-Вальтер Штайнмайер (по данным социологов, его рейтинг составил $72 \%$, тогда как рейтинг Меркель - 63\%)».

5) Факты «за» (А.Т.): «Но сейчас с подачи канцлера Штайнмайер выдвинут кандидатом на пост президента Германии, чему он сам после своих резких высказываний в адрес Дональда Трампа, надо полагать, только рад (в ФРГ, являющейся парламентской республикой, президент имеет весьма ограниченные полномочия и исполняет в основном представительские функции; так что Штайнмайер, если действительно станет главой немецкого государства, впредь сможет с Трампом и не общаться напрямую)».

Других же, кроме Меркель, кандидатов на канцлерский пост в общем-то и не усматривается.

6) Факты «против» (А.Т.): «Правда, некоторые немецкие СМИ в качестве возможных претендентов называют президента Европарламента социал-демократа Мартина Шульца, чей срок пребывания в этой должности истекает в январе 2017 года, и действующего вицеканцлера ФРГ, министра экономики и энергетики, председателя СДПГ Зигмара Габриэля».

7) Факты «за» (А.Т.): «Но их шансы, если верить социологическим опросам, по сравнению с Меркель значительно ниже: за Шульца в октябре высказались $29 \%$ респондентов, за Габриэля и того меньше - 18\%. К тому же следует иметь в виду, что в Германии канцлера выбирают не прямым голосованием: в результате парламентских выборов его кандидатуру предлагают победившие партии».

Далее следует заключительный вывод, подтверждающий и уточняющий основную мысль (основной тезис) изложенного в публикации прогноза:

«Так что вопрос следует ставить не так: «пойдёт ли Меркель на выборы в четвёртый раз?», а так: «победит ли возглавляемая ею партия ХДС?..».

Как видим, в данном случае автор показывает наиболее важные события в политической жизни страны, так или иначе связанные с 
возможностью Меркель баллотироваться на выборах на пост канцлера Германии. Каждое из этих событий может быть причиной, либо позитивных, либо негативных последствий, способных повлиять на итоги предстоящих выборов. Причинно-следственные связи, возникающие при этом, достаточно очевидны, прежде всего, для искушенной в политических баталиях аудитории. Автор, судя по всему, полагает, что причин, способствующих решению Меркель идти на выборы, по крайней мере, на данном этапе, больше, нежели причин, противостоящих такому решению. И аудитория вполне может принять такую его убежденность. В любом случае, она может самостоятельно оценить шансы Меркель на выборах, исходя из той картины (причинно-следственных связей), существующей в политической жизни страны, которая представлена в тексте.

Отдельным вариантом причинно-следственного анализа, используемым в процессе прогнозирования в СМИ, можно считать «метод сценариев» ${ }^{1}$. Этот метод применяется, когда рассматриваются сложные ситуации (экономические, политические и пр.), включающие в себя в качестве составных частей определенные группы разнообразных фракторов. В случае, если превалирующее развитие получит одна группа фракторов, ситуация в будущем получит одни очертания, если другая группа - другие очертания, третья группа -третьи очертания и т. д. Описываемые в тексте возможные варианты развития си-

\footnotetext{
${ }^{1}$ Метод сценариев. Принятие управленческих решений. URL : http://decisionmake.ru/ index.php?action=full_article\&id=63.
}

туации и обозначаются как «сценарии». В основе каждого «сценария» лежит определенная связь между факторами, выступающими как причины определенных следствий, способных проявиться в будущем. Уверенность автора в том, что возникнут именно те или иные следствия, базируется на имеющемся опыте, показывающем, что определенные причины всегда порождают определенные следствия. Разумеется, что по ходу развития прогнозируемой ситуации, могут возникать некоторые непредвиденные обстоятельства, которые способны искажать прогнозируемый результат, но это не исключает возможности применения метода сценариев в прогнозировании, а лишь указывает на его сложность.

Следующий метод - «прогнозирование по аналогии»². Напомним, что понятие «аналогия» в переводе с греческого («analogia») означает совпадение соотносимых явлений в определенных отношениях. В логике под аналогией понимается метод познания, представляющий собой, основанное на установленном сходстве, соотносимых предметов в ряде их качеств, традуктивное умозаключение о том, что и другие их качества также совпадают. Схематически умозаключение по аналогии выглядит так:

«Объект В обладает признаками a, b, c, d, e; объект C обладает признаками b, с, b, e; следовательно, объект C, вероятно, обладает признаком а» [8, с. 20].

В процессе аналогии, происходит перенесение признаков с одного

2 Прогнозирование по аналогии. URL: http://ru-ecology.info/post/100955203350003/. 
(уже изученного) соотносимого явления на другое - изучаемое. Нередко аналогию понимают как обычное сравнение, что неправильно, поскольку аналогия всегда проводится между предметами одного класса и только по уже обнаруженным совпадающим признакам, с целью установления совпадения других признаков этих предметов. Сравнение же может проводиться между предметами разных классов и не только по сходным чертам, но и по различным, а цель сравнения, соответственно состоит, как в установлении сходства, так и - различия между соотносимыми предметами.

Аналогии как метод прогнозирования используется в журналистике очень часто. Объяснить это можно в первую очередь тем, что данный метод дает возможность быстро формулировать тот или иной прогноз, исходя из уже известного, аналогичного по классу знания. Аналогии бывают разных видов:

1) простая аналогия - означает, что журналист, обнаружив сходство двух соотносимых явлений в одних чертах, делает вывод о сходстве и других черт этих явлений;

2) распространенная аналогия - это умозаключение, исходящее из того, что сходство каких-то качеств, соотносимых явлений, означает и сходство вызвавших их причин;

3) нестрогая аналогия означает переход от сходства ряда признаков соотносимых явлений к сходству их в каком-то новом признаке, о котором неизвестно, связан ли он с уже отмеченными признаками;

4) строгая аналогия означает переход от сходства соотносимых явлений в каком-то признаке к сход- ству их в другом признаке, зависящем от первого.

Независимо от того, какого вида аналогию будет применять журналист, он должен соблюдать правила, которые значимы в этом случае, а именно:

1) Выяснить, относятся ли соотносимые явления к одному и тому же классу? Если нет, то аналогия невозможна. 2) Определить, какие из признаков соотносимых явлений относятся к существенным и найти их как можно больше.

3) Установить, действительно ли между такими признаками соотносимых явлений есть сходство? 4) Найти связь обнаруженных сходных признаков соотносимых явлений тем, относительно которого будет сделан вывод. 5) Исходить из того, что невозможна аналогия, ведущая к заключению о сходстве всех признаков, соотносимых явлений. 6) Не забывать о том, что аналогия, основанная на второстепенных (несущественных) признаках соотносимых явлений, может приводить к заблуждениям.

Теперь рассмотрим применение метода аналогии в прогностическом журналистском тексте С. Рыбаса «Столыпин как зеркало для Владимира Путина» [9, с. 2]. Автор данной публикации начинает изложение своих мыслей с описания основных качеств Петра Столыпина, как государственного деятеля:

«Кто такой Столыпин? Сегодня его можно назвать выходцем из спецслужб. Премьер-министром он стал после того, как был министром внутренних дел в правительстве Горемыкина, а, став премьером, сохранил этот пост и руководил по- 
лицией и жандармами. По политическим взглядам - либерал... По происхождению - выходец из правящей элиты. Его отец - генерал, командовал корпусом в русско-турецкую войну 1877-1878 гг., был защитником Севастополя, где подружился с юным артиллеристом Львом Толстым, своим дальним родственником. Кроме того, Петр Столыпин приходится троюродным братом Михаилу Лермонтову.

Столыпин окончил Санкт-Петербургский университет и начал службу чиновником министерства государственных имуществ в департаменте земледелия и сельской промышленности в должности помощника столоначальника. Потом, переезд в свое имение Колноберже в Литве, избрание уездным предводителем дворянства, затем назначение Ковенским губернатором, Саратовским губернатором, министром внутренних дел, премьером. Лично очень смелый, дрался на дуэли и всю жизнь носил ее метку на поврежденной правой руке. Мог без охраны войти в бунтующую толпу и успокоить ее. На него было девять покушений. В завещании он пророчески написал: «Похороните там, где меня убьют...». И т. п.

Характеристике основных достижений П. Столыпина автор посвятил большую часть своей публикации, сделав следующий промежуточный вывод:

«Столыпин ушел из жизни не понятый ни старой элитой, ни новой эпохой. Поэтому его опыт сегодня может послужить своеобразным зеркалом для постельцинских времен».

Что касается личности В. Путина, то подробного её описания, подобного описанию личности П. Столыпи- на, он не дает. Это можно объяснить тем, что В. Путин является нашим современником и многое из его биографии и свершенных им дел, нам хорошо известно. Поэтому автор вполне логично обращается далее к аналогии между П. Столыпиным и В. Путиным:

«Во-первых, оба - близки спецслужбам.

Во-вторых, оба нацелены на решение внутренних проблем и для обоих не пустой звук выражения: «Дайте России 20 лет мира, и вы не узнаете ее». Действия Столыпина во время Боснийского кризиса 1909 г., когда он был категорически против втягивания страны в войну на Балканах, и действия Путина во время недавнего кризиса в Югославии имеют общую почву.

В-третьих, к обоим одинаково плохо относятся правые и левые. Как Столыпин, так и Путин стремится к гармонизации внутренней жизни, ее развитию без революционных потрясений. В-четвертых, оба - консервативные либералы и патриоты, открыто говорящие о своей любви к России как о главной мотивации.

В-пятых, оба одиноки, их команды малочисленны.

Какой же вывод можно сделать из горькой судьбы реформатора?

Самый главный: у реформаторов в нашей стране никогда не хватало времени. Для Путина скоро начнется предцейтнотная пора. Перед следующими президентскими выборами правые открыто бросят ему вызов. А что будет дальше - Бог ведает».

В данном случае автор применил простую нестрогую аналогию, предполагающую вероятностный вывод. Вместе с тем, данная аналогия проведена с учетом наиболее 
важных требований, которые предъявляются к ней со стороны логики. А именно: 1) аналогия проводится между явлениями одного класса; 2) признаки соотносимых явлений, по которым проводится аналогия, относятся к разряду существенных. Причем, автору удалось установить пять признаков данного рода, что является приемлемым основанием для результирующего вывода о будущем одного из соотносимых феноменов.

По приведенному отрывку текста вполне можно судить о том, что аналогия как метод прогнозирования, позволяет аудитории ясно увидеть все соотносимые качества двух государственных деятелей, очевиден и сам вывод, следующий из проведенного соотношения. Это, конечно же, намного повышает возможность доверия аудитории к составленному автором прогнозу. Хотя, надо иметь в виду, что сама по себе обоснованность, логичность вывода не всегда гарантирует согласие с ним тех или иных представителей аудитории. Препятствием на пути такого согласия может выступать, например, их идеологическая предубежденность, политическая ангажированность и пр.

Теперь рассмотрим, как применяется в ходе прогнозирования явлений «метод экстраполяции». Слово «экстраполяция» («от лат. extra - вне и polatio - подновление, изменение») [10, с. 1518.] означает «распространение выводов, полученных из наблюдений над одной частью явлений на другую часть его» [Там же]. Существуют разные виды экстраполяции. Для прогнозирования в журналистике важна экстраполяция, представляющая собой распространение основных тенденций развития обсуждаемого феномена на его будущее (на прогнозируемый период). В основе экстраполяции тенденций развития данного явления на последующее его состояние лежит наша уверенность в том, что выявленная тенденция окажется устойчивой и в будущем. Такого рода прогнозирование считается наиболее оправдывающим себя [11, с. 558].

Судить о существовании той или иной тенденции журналист может в случае, если обнаружится определенная, взаимосвязанная совокупность фрактов, имеющая четкий вектор развития. Видя такой вектор, автор как раз и может утверждать о том, к чему приведет это развитие в будущем. Конкретный пример прогнозировании с помощью экстраполяции, содержит, например, публикации «Жизнь после «отжима»: что ждет отобранные предприятия в ЛНР и ДНР?» $[12$, с. 1]. Главную мысль - прогноз о будущей судьбе угольных и металлургических предприятий ДНР и ЛНР автор излагает уже в начале текста:

«Угольные и металлургические предприятия Донбасса, в случае их «отжима» и незаконной смены собственников, имеют реальный шанс стать экономически несостоятельными, с перспективой их полной остановки или консервации. Расположенные на его территории заводы и шахты сейчас находятся в крайне тяжелом положении.

Блокада ЛНР/ДНР с украинской стороны уже привела к снижению оборотов на многих предприятиях, но попытка переориентировать горно-металлургический комплекс на Россию может поставить крест на 
перспективах тяжелой промышленности региона».

Далее следует описание той главной тенденции, сложившейся на мировом рынке металлопродукции, которая объясняет, почему, собственно говоря, автор и делает данный прогноз дальнейшего состояния отрасли:

«Согласно прогнозу Worldsteel, в 2017-2018 годах можно ожидать падения спроса в мире на железную руду и черные металлы на 1-2\% в год.

Замедление роста мировой экономики и снижение внутреннего спроса в Китае привели к снижению потребления металлопродукции В этой стране. На китайском рынке начали образовываться большие излишки металла, которые были направлены на экспорт. Таким образом, из импортера металла Китай стал его крупным экспортером.

В результате снижения мирового спроса цены на металл мире с 2014 года снизились на 20-30\%. Доходы от экспорта черных металлов также продолжают снижаться. По данным Федеральной таможенной службы России в 2016 году экспорт черных металлов вырос на 3,5\% и составил 42,8 млн тонн. При этом поступления от экспорта в долларовом выражении снизились на $10,5 \%$ в сравнении с показателем предыдущего года.

Из-за экономического снижения второй год подряд спрос на продукцию металлургов на внутреннем рынке России также снижается. По данным Росстата, снижение экономики России в прошлом году составило 0,2\%, по оценкам Минэкономразвития - она снизилась на 0,6\%. По оценкам экспертов рынка, при нулевом уровне ВВП в России, ежегодное снижение спроса на металл составляет 2-3\%. Повысить спрос на металл на внутреннем рынке можно за счет реализации масштабных инфраструктурных проектов с участием государства, чего сейчас не происходит».

Далее автор ещё раз подчеркивает, к чему приведет тенденция снижения спроса на металл в мире в целом и, в частности, в России, применительно к будущему состоянию металлургических предприятий Донбасса, в случае переориентации их производства на российский рынок:

«В условиях сокращения спроса открытие российского рынка для поставок металла из оккупированных территорий Донбасса приведет к росту конкуренции, демпингу, и резкому снижению доходов российских компаний. Внутренний рынок России сжимается и обеспечить заказами дополнительные поставки из Донбасса не получится...».

Этот вывод в смысловом плане повторяет сформулированный в начале данной публикации прогноз об отсутствии перспектив у тяжелой промышленности региона, в случае ухода её из-под юрисдикции Украины. Однако, данный прогноз может оправдаться только в том случае, если по-прежнему будут действовать факторы, способствующие негативной тенденции спроса на металл на мировом рынке и в России. Если же такие факторы перестанут существовать, и возникнет иная тенденция со сбытом металла, то и данный прогноз может оказаться ошибочным. Понимание этого, очевидно, поможет аудитория увидеть условность (содержащегося в публикации) прогностического 
вывода о судьбе металлургических предприятий Донбасса, переориентирующихся на рынок России.

Следующий метод - «экспертных оценок» [13, с. 23-24]. часто применяется при прогнозировании развития особо сложных ситуаций (например, в фринансово-экономической сфере). Доверие к мнениям экспертов со стороны аудитории держится на доверии к самим экспертам как специалистам в конкретной области. Чем выше их авторитет, тем больше значит для аудитории мнение эксперта. Как показывает практика, авторы публикаций в современных СМИ (прежде всего деловых) активно обращаются к экспертным оценкам не одного, а многих экспертов. Подобный пример содержится в статье «Доллар по 80 рублей: что ждет экономику России в 2016 году?» ${ }^{3}$. Вот отрывок из неё:

«Половина экономистов и аналитиков, опрошенных РБК (16 из 32 участников опроса), уверены, что экономика России в 2016 году сократится, еще пятеро предсказывают нулевой рост. Согласно консенсус-прогнозу РБК, в следующем году ВВП снизится на 0,2\%. Фундаментальное влияние на российскую экономику в 2016 году окажет сокращение потребительского спроса, уверен главный экономист ПФ "Капитал" Евгений Надоршин: "Спрос снизится из-за высокой инфляции, тяжелых условий получения кредитов, сокращения реальных доходов и недостатка сбережений".

Согласно консенсус-прогнозу, инфляция на конец 2016 года со-

${ }^{3}$ Доллар по 80 рублей: что ждет экономику России в 2016 году? URL : http: //www. rbc.ru/finances/28/12/2015/567a71239a79474 74e041de4. ставит 8,1\%... Для российского потребителя дно кризиса пока не пройдено, согласна экономист по России Standard \& Poor's Татьяна Лысенко. Инвестиционная активность будет низкой, добавляет начальник аналитического управления банка "Зенит" Владимир Евстифеев: "Перспектива сохранения низкого спроса лишает компании стимулов для развития, заставляя удерживать капитальные расходы на минимально необходимом уровне". Основной риск 2016 года - цены на нефть, говорит Лысенко: “Сохранение цен на текущих низких уровнях, а тем более их дальнейшее падение, повлечет за собой очередной виток ослабления рубля и всплеска инфляции...”. Из-за низких цен на нефть рецессия в России продлится в 2016 году, говорит главный экономист по развивающимся рынкам Capital Economics Лиза Ермоленко. "Падение цен на нефть на \$10 за баррель сокращает экспортные доходы бюджета на \$25 млрд, или 2\% ВВП...”.

11 из 32 экспертов уверены в росте экономики России в 2016 году. Аналитик УК “Альфа-Капитал” Андрей Шенк считает, что цена на нефть вырастет, так как сейчас ее уровень ниже себестоимости производства многих крупных игроков. По его мнению, среднегодовая цена на нефть составит \$50-60 за баррель. Это поможет ВВП вырасти на 3\% за следующий год... Главный экономист по России Royal Bank of Scotland Татьяна Орлова называет еще два фрактора, которые могут помочь российской экономике в 2016 году. Компаниям предстоит выплатить меньше внешних долгов, чем в 2015 году, поэтому отток капитала будет меньше. "Это сгладит от- 
рицательный эффрект низких цен на нефть", - говорит она... Управляющий директор Arbat Capital Алексей Голубович полагает, что доллар в моменте может вырасти до 85 руб. при цене на нефть \$25 за баррель». И т. д.

Приводя аргументы в пользу двух основных точек зрения на развитие экономики РФ, автор тем самым помогает аудитории убедиться в объективности прогнозирования. При необходимости, аудитория может сравнить доводы, и сама решить, какая точка зрения вернее.

В современной журналистике при составлении прогнозов авторы нередко прибегают к методу, который выступает как ссылка на какой-то успешный пример получения желаемого результата. Однако, сам по себе пример может быть образцом, к которому надо стремиться, но он не может быть надежной основой прогноза. Не случайно говорят: «Пример - не доказательство!». Подтверждение этому - попытка опереться на пример при прогнозировании, предпринятая в публикации «Об экспортных возможностях АПК Украины» ${ }^{4}$. Начинается публикации рассуждением автора о сегодняшней импортозависимости Украины:

«...Это касается прежде всего импорта продукции животноводства, которая в 2008 г. была равна 1,7 млрд. дол., или $27 \%$ всего импорта продукции агропродовольственного комплекса (см. табл. 1). Мы импортируем говядину (38 тыс. т), живых свиней и свинину (249 тыс. т), а также мясо птицы (262 тыс. т),

${ }^{4}$ Экспортные возможности АПК Украины. URL : http://www.sanriko.ru/seecons-385-8. html. причем за последние пять лет такой импорт возрос в 2,5 раза. И это стало главной причиной уменьшения отечественного поголовья крупного рогатого скота на $26 \%$ и свиней - на 9\%. Особенно тревожит тенденция сокращения поголовья в личных хозяйствах населения, наметившаяся в последние шесть лет. А эти хозяйства обеспечивают 60-65\% общего производства говядины и свинины, а также $82 \%$ молока... Катастрофрическая ситуация сложилась с льно-, овце- и хмелеводством, объемы производства продукции которых за два последние десятилетия сократились в 8-35 раз (рис.1) и почти все потребности Украины в этой продукции покрываются за счет импорта...» ${ }^{5}$. И т. д.

Однако, по мнению автора, в дальнейшем страна может стать крупным экспортером экологически чистой продукции сельского хозяйства, способной приносить большой доход. При этом, свой прогноз автор обосновывает ссылкой на успешный опыт данного рода, имеющийся в некоторых высокоразвитых странах Запада, в частности, в Нидерландах:

«Анализ ассортимента экспортной продукции Нидерландов впечатляет - используется все. Так, страна экспортирует пищевые отходы на сумму около 1,9 млрд. дол., что составляет почти 20\% всего экспорта продукции агропродовольственного комплекса Украины; импортирует картофель на 252 млн. дол., а экспортирует - на 677 млн., и еще быстрозамороженный - на сумму 1357 млн. дол. И этот перечень можно продолжать долго: продукты

${ }^{5}$ URL : http://www.sanriko.ru/seecons385-8.html. 
питания для домашних животных экспортируются на 705 млн. дол. (во Франции эта продукция вообще занимает седьмую позицию в структуре экспорта - 2,4 млрд.); продукты для детей - на 406 млн. дол. и т. д. Слабой стороной структуры экспорта продукции агропродовольственного комплекса Украины является ее небольшой ассортимент: если в Нидерландах десять главных видов экспортной продукции занимают 40\%, то в Украине - более $75 \%$...» ${ }^{6}$. И т. д.

Затем следует сравнение достижений в производстве сельхозпродукции в странах Запада и в Украине, обнаруживающее, ещё более резкое её отставание:

«...Если по урожайности основных культур Украина отстает от стран ЕC в 2 раза и от США - в 1,5, то по продуктивности скота и птицы - соответственно, в 2 и 3 раза. Значительное отставание наблюдается также в отношении трудо-, энерго-

${ }^{6}$ URL : http://www.sanriko.ru/seecons385-8.html. и капиталоемкости продукции...» ${ }^{7}$. И т. п.

Таким образом, опыт Запада, описанный автором, говорит о том, что производство сельхозпродукции там развито хорошо, в отличие от Украины, и что этот опыт, якобы, может должен быть повторен украинскими производителями. Но из высоких достижений западных стран никак не следует, что такие же результаты будут достигнуты и на Украине, и что она станет крупнейшим конкурентом Запада по экспорту экологически чистой сельхозпродукции. Очевидно автору не удалось заметить отсутствие причинно-следственной связи между успехами западных стран и прогнозируемым состоянием будущего сельхозпроизводства Украины. То есть, того, что его прогноз не имеет реального основания и вряд ли может быть с доверием принят аудиторией, которая заметит это.

7 Там же.

\section{СПИСОК ИСПОЛЬЗОВАННОЙ ЛИТЕРАТУРЫ}

1. Белякова Л. Свобода аналитического творчества в условиях государственного регулирования СМИ / Л. Белякова // Журналістыка-2016. Стан, праблемы і перспектывы : матэрыялы 18-й Міжнар. нав.-практ. канф. 10-11 лістопада. Мінск. 2016. - С. 54-57.

2. Сидоров В. А. Политический прогноз в журналистике [Электронный ресурс] / В. А. Сидоров. - Режим доступа: http://www.jf.spbu.ru/upload/files/file_1421063545_009.pdf.

3. Brendel D. Yournalistisches Grundwissen / D. Brendel, B. E. Grobe. - Munchen ; Dortmund, 1976.

4. Пашкова Н. А. Основные методы прогнозирования, используемые при государственном регулировании экономики на современном этапе / Н. А. Пашкова // Российское предпринимательство. - 2006. — № 9 (81). - С. 43-45.

5. Тертычный А. А. Аналитическая журналистика: познавательно-психологический подход : монография / А. А. Тертычный. - М. : Гендальф, 1998. - 255 с. $206 \mathrm{c}$.

6. Хоменко Е. А. Логика : учеб. пособие / Е. А. Хоменко. - М. : Воениздат, 1976. -

7. Дебрер С. Кого Путин выберет канцлером Германии [Электронный ресурс] / C. Дебрер. - Режим доступа: http://svpressa.ru/politic/article/160873/.

8. Философрский словарь / под ред. И. Т. Фролова. - 6-е изд. - М. : Политиздат, 1991. - $560 \mathrm{c}$.

9. Рыбас С. Столыпин как зеркало для Владимира Путина / С. Рыбас // Независимая газета. - 2001. - 22 февр. 
10. Большой толковый словарь русского языка / отв. ред. С. А. Кузнецов. - СПб. : Норинт, 2000. - 1534 с.

11. Бестужев-Лада И. Социальное прогнозирование / И. Бестужев-Лада // Социология в России / отв. ред. В. А. Ядов. - 2-е изд., перераб. и доп. - М. : Ин-т социологии РАН, 1998. - С. 558-610.

12. Ежель А. Жизнь после «отжима»: Что ждет отобранные предприятия в ЛНР и ДНР? [Электронный ресурс] / А. Ежель. - Режим доступа : http://news.finance.ua/ru/ news/-/396599/zhizn-posle-otzhima-chto-zhdet-otobrannye-predpriyatiya-v-Inr-i-dnr/

13. Громова Н. М. Основы экономического прогнозирования : учеб. пособие / Н. М. Громова Н. И. Громова. - М. : Акад. Естествознания, 2007. - 112 с.

\section{REFERENCES}

1. Belyakova L. Freedom of Analytical Creativity in the Context of the Government Control of the Media. Zhurnalistyka-2016. Stan, prablemy i perspektyvy : materyyaly 18-i Mizhnarodnai navukova-praktychnai kanferentsyi 10-11 listopada [The Current State, Problems and Prospects. Materials of the 18th International Research Conference, November 10-11]. Minsk, 2016, pp. 54-57. (In Russian).

2. Sidorov V. A. Politicheskii prognoz v zhurnalistike [Political Forecasting in Journalism]. Available at: http://www.jf.spbu.ru/upload/files/file_1421063545_009.pdf. (In Russian).

3. Brendel D., Grobe B. E. Yournalistisches Grundwissen. Munchen, Dortmund, 1976.

4. Pashkova N. A. The Main Methods of Forecasting Used under Government Regulation of Economy Nowadays. Rossiiskoe predprinimatel'stvo = Russian Entrepreneurship, 2006, no. 9 (81), pp. 43-45. (In Russian).

5. Tertychnyi A. A. Analiticheskaya zhurnalistika: poznavatel'no-psikhologicheskii podkhod [Analytical Journalism: The Cognitive-Psychological Approach]. Moscow, Gendal'f Publ., 1998. 255 p.

6. Khomenko E. A. Logika [Logic]. Moscow, Voenizdat Publ., 1976. 206 p.

7. Debrer S. Kogo Putin vyberet kantslerom Germanii [Whom will Putin Choose as Chancellor of Germany]. Available at: http://svpressa.ru/politic/article/160873/. (In Russian).

8. Frolov I. T. (ed.). Filosofskii slovar' [Philosophical Dictionary]. $6^{\text {th }}$ ed. Moscow, Politizdat Publ., 1991. 560 p.

9. Rybas S. Stolypin as a Mirror for Vladimir Putin. Nezavisimaya gazeta $=$ Independent Newspaper, 2001, February 22. (In Russian).

10. Kuznetsov S. A. (ed.). Bol'shoi tolkovyi slovar' russkogo yazyka [The Great Dictionary of Russian language]. Saint Petersburg, Norint Publ., 2000. 1534 p.

11. Bestuzhev-Lada I. Social Forecasting. In Yadov V. A. (ed.). Sotsiologiya v Rossii [Socilology in Russia]. $2^{\text {nd }}$ ed. Moscow, Sociology Institute of Russian Academy of Sciences Publ., 1998, pp. 558-610. (In Russian).

12. Ezhel' A. Zhizn' posle «otzhima»: Chto zhdet otobrannye predpriyatiya v LNR i DNR? [Life after "Grabbing Assets»: What Awaits Grabbed Enterprises in the Luhansk People's Republic and the Donetsk People's Republic]. Available at: http://news.finance.ua/ru/news//396599/zhizn-posle-otzhima-chto-zhdet-otobrannye-predpriyatiya-v-Inr-i-dnr/. (In Russian).

13. Gromova N. M., Gromova N. I. Osnovy ekonomicheskogo prognozirovaniya [Basics of Economic Forecasting]. Moscow, Russian Academy of Natural History Publ., 2007. 112 p.

\section{БИБЛИОГРАФИЧЕСКОЕ ОПИСАНИЕ СТАТЬИ}

Тертычный А. А. Прогноз в журналистском тексте: особенности обоснования / А. А. Тертычный // Вопросы теории и практики журналистики. - 2017. - Т. 6, № 3. C. 306-319. DOI: 10.17150/2308-6203.2017.6(3).306-319.

\section{REFERENCE TO ARTICLE}

Tertychnyi A. A. Forecasts in Journalistic Texts: Specific Criteria for Grounding. Voprosy teorii i praktiki zhurnalistiki $=$ Theoretical and Practical Issues of Journalism, 2017, vol. 6, no. 3, pp. 306-319. DOI: 10.17150/2308-6203.2017.6(3).306-319. (In Russian). 